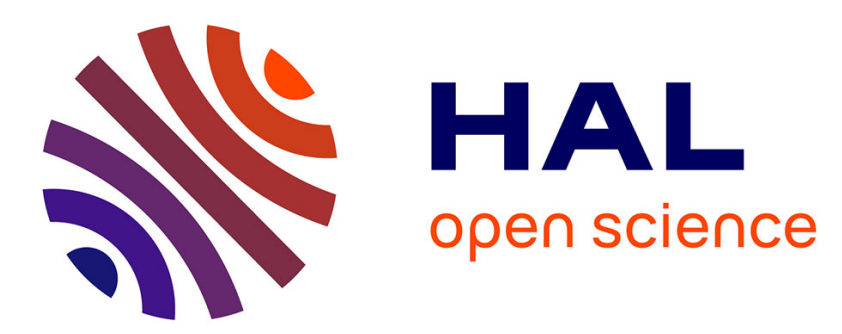

\title{
Modelling of fluxon dynamics in stacked Josephson tunnel junctions
}

\author{
A. Ustinov, A. Petraglia, N. Pedersen
}

\section{To cite this version:}

A. Ustinov, A. Petraglia, N. Pedersen. Modelling of fluxon dynamics in stacked Josephson tunnel junctions. Journal de Physique IV Proceedings, 1994, 04 (C6), pp.C6-279-C6-280. 10.1051/jp4:1994645 . jpa-00253141

\section{HAL Id: jpa-00253141 https://hal.science/jpa-00253141}

Submitted on 1 Jan 1994

HAL is a multi-disciplinary open access archive for the deposit and dissemination of scientific research documents, whether they are published or not. The documents may come from teaching and research institutions in France or abroad, or from public or private research centers.
L'archive ouverte pluridisciplinaire HAL, est destinée au dépôt et à la diffusion de documents scientifiques de niveau recherche, publiés ou non, émanant des établissements d'enseignement et de recherche français ou étrangers, des laboratoires publics ou privés. 


\title{
Modelling of fluxon dynamics in stacked Josephson tunnel junctions
}

\author{
A.V. Ustinov, A. Petraglia* and N.F. Pedersen* \\ Institut of Thin Films and Ion Technology, Research Centre, KFA, D-52428 Jülich, Germany \\ * Physics Department, Technical University of Denmark, 2800 Lyngby, Denmark
}

In previous studies of long Josephson junctions, several planar coupling mechanisms have been proven to synchronize fluxon motion in individual junctions at a particular frequency [1]. The coupling strength is a function of the distance between junctions, and consequently limited by the lateral resolution of modern lithography. Vertical stacking of superconducting thin-film devices appears to be an obvious way of their integration. The inductive coupling between the adjacent junctions in a stack can be by several orders of magnitude stronger than in the planar case. The coupling is determined by the thickness $d$ of the superconducting layer between the junctions.

Our simulations are related to recent experimental studies of flux-flow resonances in stacked $\mathrm{Nb} / \mathrm{Al} / \mathrm{AlO}_{x} / \mathrm{Nb}$ junctions $[3,4]$. In agreement with these experiments, the simulations indicate a splitting of the dispersion relation in two branches, each of them corresponding to fluxons moving with different Swihart velocities. In addition, the simulated current-voltage characteristics of the stack display the phase-locked flux-flow resonances of two junctions which were previously observed experimentally. These data support a possibility of application of the stacked long Josephson junctions as local oscillators for millimeter and sub-millimeter wave cryoelectronic circuits.

We investigate numerically the magnetic flux dynamics in a system of two vertically stacked long Josephson junctions. The model is based on the approach by Sakai et al. [2] and is described by two coupled perturbed sine-Gordon equations:

$$
\frac{1}{1-S^{2}} \frac{\partial^{2} \varphi_{A, B}}{\partial x^{2}}-\frac{\partial^{2} \varphi_{A, B}}{\partial t^{2}}=\sin \varphi_{A, B}+\alpha \frac{\partial \varphi_{A, B}}{\partial t}+\gamma_{A, B}+\frac{S}{1-S^{2}} \frac{\partial^{2} \varphi_{B, A}}{\partial x^{2}}
$$

Here $\varphi_{A}(x, t)$ and $\varphi_{B}(x, t)$ are the superconducting phase differences across the junctions $A$ and $B$, respectively. The spatial coordinate $x$ is normalized to the single-junction Josephson penetration depth $\lambda_{J}$, the time $t$ to the inverse plasma frequency $\omega_{0}^{-1}, \alpha$ is the dissipation coefficient, $\gamma_{A}$ and $\gamma_{B}$ are the bias currents. The coupling parameter $S$ can be calculated from experimentally measurable values [2]:

$$
S=-\frac{\lambda_{L}}{\left[d_{0}+\lambda_{L}+\lambda_{L} \operatorname{coth}\left(d / \lambda_{L}\right)\right] \sinh \left(d / \lambda_{L}\right)}
$$

where $d_{0}, d$, and $\lambda_{L}$ are the thickness of the insulator, the thickness of the middle electrode between the junctions, and the London penetration depth, respectively.

Both the annular and the linear junction geometry have been modelled. For the linear geometry, the calculated current-voltage characteristics in the external magnetic field clearly display two Fiske 
step voltage spacings corresponding to two different Swihart velocities for moving fluxons. This behavior is in good agreement with measured experimental data [3] .

The annular geometry has been studied in order to eliminate the influence of boundaries on fluxon interaction between the junctions. This geometry corresponds to $\mathrm{Eq}$. (1) with periodic boundary conditions:

$$
\varphi_{A}(L, t)=\varphi_{A}(0, t)+2 \pi N_{A}, \varphi_{B}(L, t)=\varphi_{B}(0, t)+2 \pi N_{B}
$$

where $N_{A}$ and $N_{B}$ are numbers of fluxons trapped in junctions $\mathrm{A}$ and $\mathrm{B}$. For the case of $N_{A} \neq 0$ and $N_{B}=0$, we find two distinct relativistic branches for fluxons moving in junction $A$. These branches are associated with the splitting of the dispersion relation for linear waves in the structure. For the case of $N_{A}=N_{B} \neq 0$, we see the phase locking of the fluxon motion in two junctions. The lower relativistic branch corresponds to the locking out-of-phase (fluxons in $A$ and $B$ repel each other), whereas the high relativistic branch accounts for the locking in-phase (fluxons in $A$ and $B$ attract each other). This result is in agreement with the stability analysis of the bunched singlefluxon solutions in coupled junctions [5]. Our conclusion is that the phase-locked fluxon resonances experimentally observed in Ref. [4] account for the out-of-phase locking of moving fluxon arrays in two junctions.

We thank P. Bodin for providing us the numerical code of his program, and also R. Kleiner and S. Sakai for useful discussions. The work was partially supported by the NATO grant LG-920672.

\section{References}

[1] R. Monaco, S. Pagano, and G. Costabile, Phys. Lett. A 131, 122 (1988); T. Holst, J. Bindslev Hansen, N. Gronbech-Jensen, and J. A. Blackburn, Phys. Rev. B 42, 127 (1990); M. Cirillo, I. Modena, F. Santucci, P. Carelli, and R. Leoni, Phys. Lett. A 167, 175 (1992).

[2] S. Sakai, P. Bodin, and N. F. Pedersen, J. Appl. Phys. 73, 2411 (1993).

[3] A. V. Ustinov, H. Kohlstedt, M. Cirillo, N. F. Pedersen, G. Hallmanns, and C. Heiden, Phys. Rev. B 48, 10614 (1993).

[4] A. V. Ustinov, H. Kohlstedt, and C. Heiden, to be published (1993).

[5] N. Grønbech-Jensen, D. Cai, and M. R. Samuelsen, Phys. Rev. B 48, 16160 (1993). 